\title{
Distribution and viral load of type specific HPVs in different cervical lesions as detected by PCR-ELISA
}

\author{
M Zerbini, S Venturoli, M Cricca, G Gallinella, P De Simone, S Costa, D Santini, \\ M Musiani
}

\begin{abstract}
Aims-To investigate the distribution and viral load of the most prevalent high risk human papillomavirus (HPV) types 16, 18, 31, 33, and 45 and low risk HPV types 6 and 11 in a variety of cervical lesions.

Methods-One hundred and seventy six cytological specimens from women with different cervical lesions were investigated. For an accurate standardisation of the sample, cervical cells were counted and a volume of the cell suspension processed by polymerase chain reactionenzyme linked immunosorbent assay (PCR-ELISA). Semiquantitative determinations were achieved in relation to an external reference titration curve.

Results-HPV DNA was detected in $60.2 \%$ of the samples. HPV-16 was the prevalent genotype $(57.6 \%)$, followed by HPV-33, HPV-31, HPV-6, HPV-18, and HPV-45. HPV-11 was not detected. HPV-16 showed a pronounced increase in prevalence with the evolution of cervical disease. Semiquantitative evaluation of the results showed that only HPV-16 DNA could reach very high values $(>1000$ genome copies/cell) and a very high HPV-16 load correlated with the severity of cervical disease.
\end{abstract}

Conclusions-Only HPV-16 load appears to be associated with the severity of cervical disease.

(f Clin Pathol 2001;54:377-380)

Keywords: human papillomavirus distribution; viral load; cervical lesions

Cancer of the female genital tract is characterised by a long premalignant phase, and prevention of the disease has partially been achieved by cytological screening to identify premalignant lesions, which can be treated successfully. Epidemiological and molecular biological studies have shown a causal relation between human papillomavirus (HPV) infection and cervical neoplasia with high, intermediate or low oncogenic risk associated with different HPV genotypes. ${ }^{1}$

The association of cytological analysis with HPV detection and typing has significantly reduced the underestimation of histological alterations, and provides additional information for the follow up of patients with cytomorphologically abnormal cervical smears. ${ }^{2-4}$

In addition, increased DNA loads of high risk HPVs in cervical specimens have been proposed as a specific marker for disease, as determined by hybrid capture assay, which discriminates between high and low risk HPVs, but cannot define the specific genotype. ${ }^{3}$ Semiquantitative determinations for type specific HPV DNA have also been achieved by type specific polymerase chain reaction $(\mathrm{PCR})^{5}$ and by PCR-enzyme immunoassay, ${ }^{6}$ but discordant results have been reported mainly concerning HPV-16 DNA load with respect to cervical intraepithelial neoplasias (CIN) of different grades. Recently, quantitative type specific HPV PCR assays have shown that in patients with the same stage of disease only the amount of HPV-16 DNA differed significantly among the tested high risk HPV types 16, 18, 31, and 45; the amount of DNA increased with disease severity only for HPV-16. ${ }^{4}$

For a correct interpretation of the results this study undertook a detailed standardisation of the sample: cervical cells were counted and a volume of the cell suspension was processed by PCR-enzyme linked immunosorbent assay (ELISA). ${ }^{7}$ The assay was used to analyse the distribution and viral load of the most prevalent high risk HPV types 16, 18, 31, 33, and 45 and low risk HPV types 6 and 11 in 176 cytological specimens from immunocompetent Italian women with different cervical lesions.

\section{Methods}

CLINICAL SPECIMENS

A population of 176 Italian women with different cervical lesions and without underlying immunological diseases was selected from a larger group of women undergoing routine screening at the department of obstetrics and gynaecology, the University of Bologna.

Cytological atypia was diagnosed with the Pap test performed by staff physicians of the department of obstetrics and gynaecology using ectocervical and endocervical specimens. Specimens for the Pap test were evaluated using the standard practices of the pathology department and we accessed results from cytology records. Cytological atypia consisted of: atypical squamous cells of undetermined significance (ASCUS), low squamous intraepithelial lesions (LSIL), and high SIL (HSIL).

All 176 women were recalled for HPV testing and colposcopy with biopsy. Informed consent for the study was granted.

Cytological specimens for HPV testing were obtained as first sample by a Dracon tipped swab from the ectocervix and posterior fornix. One hundred and seventy six cervical scrapes 
were collected from the 176 subjects (mean age, 38.4 years; range, 21-69). Forty four specimens were ASCUS (mean age, 36.2 years; range, 23-69), 43 were LSIL (mean age, 34.7 years; range, 21-51), and 89 were HSIL (mean age, 36.1 years; range, 21-60).

Cells were suspended in phosphate buffered saline solution (PBS), counted, aliquoted, and cell pellets conserved at $-70^{\circ} \mathrm{C}$ until used. All 176 clinical specimens and reference clinical specimens were analysed by the PCR-ELISA method. Amplified products were also visualised by agarose gel electrophoresis. ${ }^{7}$

Experienced staff physicians performed colposcopy with biopsy. Examinations were conducted without knowledge of patients' Pap or HPV results. To obtain consensus on the histological diagnosis, a study pathologist reviewed the slides without knowledge of the diagnosis. If the first two disagreed, another pathologist reviewed the case, with no knowledge of the preceding diagnosis. A two thirds majority determined diagnostic consensus. In the histological diagnosis cervical lesions were grouped as negative, CIN I, CIN II/III, and invasive carcinoma (IC).

SAMPLE PREPARATION

Aliquots of 100000 cells from each cytological specimen were protease digested by incubation at $55^{\circ} \mathrm{C}$ for two hours in $200 \mu \mathrm{l}$ of digestion buffer (50 mM KCl, $10 \mathrm{mM}$ TrisHCl, pH 8.3, $0.05 \%$ Tween 20 , and $400 \mu \mathrm{g} / \mathrm{ml}$ of proteinase $\mathrm{K})$, followed by heat inactivation at $95^{\circ} \mathrm{C}$ for 10 minutes. A $10 \mu \mathrm{l}$ volume of each digested sample was then processed by PCR-ELISA.

DNA preparation of control samples was performed as described previously. ${ }^{7}$

PCR-ELISA METHOD

Consensus primer pair MY09 and MY11 was used in PCR amplification. ${ }^{8}$

Oligonucleotide probes specific for $\mathrm{HPV}$ types $6,11,16,18,31,33$, and 45 were used in hybridisation reactions. ${ }^{9}$ Primers GH20 and PC0 $4,{ }^{10}$ which recognise a $\beta$ globin gene sequence, were used in each PCR reaction as an amplification control, and amplified products were detected by the PC03 probe.

All the hybridisation probes used in the PCR-ELISA were 5' labelled with biotin.

DNA amplification and digoxigenin labelling were performed in $50 \mu \mathrm{l}$ of PCR reaction volume containing $10 \mu \mathrm{l}$ of each digested sample; amplified products were detected by a hybrid capture immunoassay in microtitre wells. ${ }^{7}$

Specificity, sensitivity controls, and the cut off points of the PCR-ELISA method were performed as described previously. ${ }^{7}$

Results were expressed as net absorbance after the absorbance of the buffer blank was subtracted and the index value was calculated as the optical density (OD) of the sample/OD cut off; an index value $>1$ was considered positive.

Semiquantitative determinations were achieved in relation to an external reference titration curve obtained from HeLa and CaSki cell lysates. Cell lysates containing from $5 \times 10^{1}$ to $5 \times 10^{6} \mathrm{HPV}$ DNA genome copies were analysed by PCR-ELISA and the index values determined. ${ }^{7}$

AGAROSE GEL ELECTROPHORESIS

Aliquots of $10 \mu \mathrm{l}$ of the amplified products were visualised on $2 \%$ agarose gels with ethidium bromide staining.

\section{Results and discussion}

One hundred and seventy six cervical specimens from women with different cytological atypias were analysed by PCR-ELISA. The PCR-ELISA was able to detect and type HPV-6, HPV-11, HPV-16, HPV-18, HPV-31, HPV-33, and HPV-45 DNA by hybridisation of amplified products with type specific oligoprobes. Moreover, PCR amplified products were visualised also by agarose gel electrophoresis and HPV positive samples not recognised by the type specific oligoprobes could be detected. All the 176 cervical specimens analysed could be amplified, as shown by $\beta$ globin gene amplification control.

Of the 176 cytological specimens analysed (table 1), 106 were HPV DNA positive (60.2\%); of the 106 HPV DNA positive specimens 22 were positive by agarose gel electrophoresis $(20.7 \%)$ but unreactive with the type specific oligoprobes used, whereas $84(79.2 \%)$ HPV positive specimens could be typed by the PCR-ELISA. Of the $84 \mathrm{HPV}$ type specific DNA positive specimens, eight showed the concomitant presence of two different genotypes; therefore, $92 \mathrm{HPV}$ DNAs could be typed. In the ASCUS group, one specimen was

Table 1 Presence of human papillomavirus (HPV) DNA in different cervical lesions as detected by PCR and visualised by elecrophoresis and type specific oligoprobes

\begin{tabular}{|c|c|c|c|c|c|c|c|c|c|}
\hline & \multirow{2}{*}{$\begin{array}{l}H P V \\
D N A+/ T S\end{array}$} & \multirow{2}{*}{$\begin{array}{l}\text { Untyped } \\
H P V\end{array}$} & \multicolumn{7}{|c|}{$H P V$ genotypes } \\
\hline & & & $H P V-16$ & $H P V-33$ & $H P V-31$ & $H P V-6$ & $H P V-18$ & $H P V-45$ & $H P V-11$ \\
\hline Total specimens & $\begin{array}{l}106 / 176 \\
(60.2 \%)\end{array}$ & $\begin{array}{l}22 / 106 \\
(20.7 \%)\end{array}$ & $\begin{array}{l}53 / 92 \\
(57.6 \%)\end{array}$ & $\begin{array}{l}14 / 92 \\
(15.2 \%)\end{array}$ & $\begin{array}{l}12 / 92 \\
(13.0 \%)\end{array}$ & $\begin{array}{l}7 / 92 \\
(7.6 \%)\end{array}$ & $\begin{array}{l}3 / 92 \\
(3.3 \%)\end{array}$ & $\begin{array}{l}3 / 92 \\
(3.3 \%)\end{array}$ & $\begin{array}{l}0 / 92 \\
(0 \%)\end{array}$ \\
\hline ASCUS specimens & $\begin{array}{l}12 / 44 \\
(27.3 \%)\end{array}$ & $\begin{array}{l}5 / 12 \\
(41.7 \%)\end{array}$ & $\begin{array}{l}2 / 8 \\
(25.0 \%)\end{array}$ & $\begin{array}{l}2 / 8 \\
(25.0 \%)\end{array}$ & $\begin{array}{l}3 / 8 \\
(37.5 \%)\end{array}$ & $\begin{array}{l}1 / 8 \\
(12.5 \%)\end{array}$ & $\begin{array}{l}0 / 8 \\
(0 \%)\end{array}$ & $\begin{array}{l}0 / 8 \\
(0 \%)\end{array}$ & $\begin{array}{l}0 / 8 \\
(0 \%)\end{array}$ \\
\hline LSIL specimens & $\begin{array}{l}23 / 43 \\
(53.5 \%)\end{array}$ & $\begin{array}{l}8 / 23 \\
(34.8 \%)\end{array}$ & $\begin{array}{l}6 / 17 \\
(35.3 \%)\end{array}$ & $\begin{array}{l}4 / 17 \\
(23.5 \%)\end{array}$ & $\begin{array}{l}2 / 17 \\
(11.8 \%)\end{array}$ & $\begin{array}{l}4 / 17 \\
(23.5 \%)\end{array}$ & $\begin{array}{l}0 / 17 \\
(0 \%)\end{array}$ & $\begin{array}{l}1 / 17 \\
(5.9 \%)\end{array}$ & $\begin{array}{l}0 / 17 \\
(0 \%)\end{array}$ \\
\hline HSIL specimens & $\begin{array}{l}71 / 89 \\
(79.8 \%)\end{array}$ & $\begin{array}{l}9 / 71 \\
(12.7 \%)\end{array}$ & $\begin{array}{l}45 / 67 \\
(67.2 \%)\end{array}$ & $\begin{array}{l}8 / 67 \\
(11.9 \%)\end{array}$ & $\begin{array}{l}7 / 67 \\
(10.4 \%)\end{array}$ & $\begin{array}{l}2 / 67 \\
(3.0 \%)\end{array}$ & $\begin{array}{l}3 / 67 \\
(4.5 \%)\end{array}$ & $\begin{array}{l}2 / 67 \\
(3.0 \%)\end{array}$ & $\begin{array}{l}0 / 67 \\
(0 \%)\end{array}$ \\
\hline
\end{tabular}

Untyped HPV: HPV DNA positive specimens visualised by electrophoresis but unrecognised by type specific oligoprobes. HPV genotypes: HPV DNA positive specimens recognised by type specific oligoprobes in hybridisation assays.

ASCUS, atypical squamous cells of undetermined significance; HSIL, high risk squamous intraepithelial lesion; LSIL, low risk squamous intraepithelial lesion; TS, tested specimens. 
positive both for HPV-16 and HPV-31; among the LSIL group, two specimens were positive both for HPV-6/HPV-16 and HPV-6/HPV-33 DNA; and in the HSIL group, five specimens showed the concomitant presence of HPV-16/ HPV-31, HPV-16/HPV-33, HPV-16/HPV-45, HPV-16/HPV-18, and HPV-31/HPV-33 DNA. Table 1 reports the distribution of different HPV genotypes in relation to cytology.

When the prevalence was analysed in relation to the severity of cervical lesions from ASCUS to HSIL, the prevalence was $27.3 \%$, $53.5 \%$, and $79.8 \%$ respectively, increasing with disease progression.

However, in accordance with recent data, ${ }^{4}$ the trend was mainly influenced by HPV-16, which was the prevalent genotype (57.6\%), and showed a clear increase in prevalence with the evolution of cervical disease from ASCUS to HSIL: $25.0 \%, 35.3 \%$, and $67.2 \%$, respectively. The prevalence of HPV-16 was significantly higher $(p<0.01)$ in HSIL than in ASCUS and LSIL. HPV-18 was detectable only in the HSIL group with a prevalence of $4.5 \%$. The absence of HPV-18 in low grade cervical lesions could result from the low prevalence of HPV-18 in the study population; alternatively, a short premalignant phase could be hypothesised. ${ }^{1}$ Other HPV genotypes not recognised by the specific oligoprobes used showed an overall prevalence of $20.7 \%$. It is interesting that the prevalence from ASCUS to HSIL was $41.7 \%, 34.8 \%$, and $12.7 \%$, respectively, indicating that most of the other HPV types were poorly associated with increasing severity of the disease.

The histological diagnosis was used for additional data analysis. Histologically negative specimens were present in $54.5 \%$ and $2.3 \%$ of the ASCUS and LSIL groups, respectively. Of the histologically negative specimens, only two $(8 \%)$ were HPV DNA positive, both in the ASCUS group.

CIN I lesions could be detected in $31.8 \%$ and $90.7 \%$ of the ASCUS and LSIL groups, respectively; $34.0 \%$ of the CIN I specimens were HPV DNA positive.

CIN II/III lesions were diagnosed in $13.6 \%$, $7.0 \%$, and $93.2 \%$ of the ASCUS, LSIL, and HSIL groups, respectively; $78.3 \%$ of CIN II/III specimens were HPV DNA positive. Invasive carcinomas were detected in $6.7 \%$ of the HSIL group and all of them were HPV DNA positive.

Figure 1 shows the distribution of single type specific HPV positive samples in CIN I, CINII/III, and IC groups.

To compare semiquantitative data, cervical samples were normalised by cell counting and HPV DNA content expressed as HPV genome copies/sample. Because a different number of cells can be present in different cervical samples and the amount of cellular DNA increases significantly with the progression of cervical disease status, for the comparative evaluation of quantitative results it seems necessary to standardise the sampling and to normalise the sample content. ${ }^{4}$

Figure 1 shows the distribution of index values for HPV types $6,11,16,18,31,33$, and 45 in the CIN I, CIN II/III, and IC groups. The amount of HPV DNA/specimen varied widely within a single group and between the different groups with several HPV DNA genome copies distributed within a $4 \log$ interval for the specimens of the CIN I group and over a $6 \log$ interval for the specimens of either the CIN II/III or IC groups. The presence of dispersed values was more evident with the progression of cervical lesions and accounted for the increase in the mean index value, which was $5.9,10.6$, and 12.1

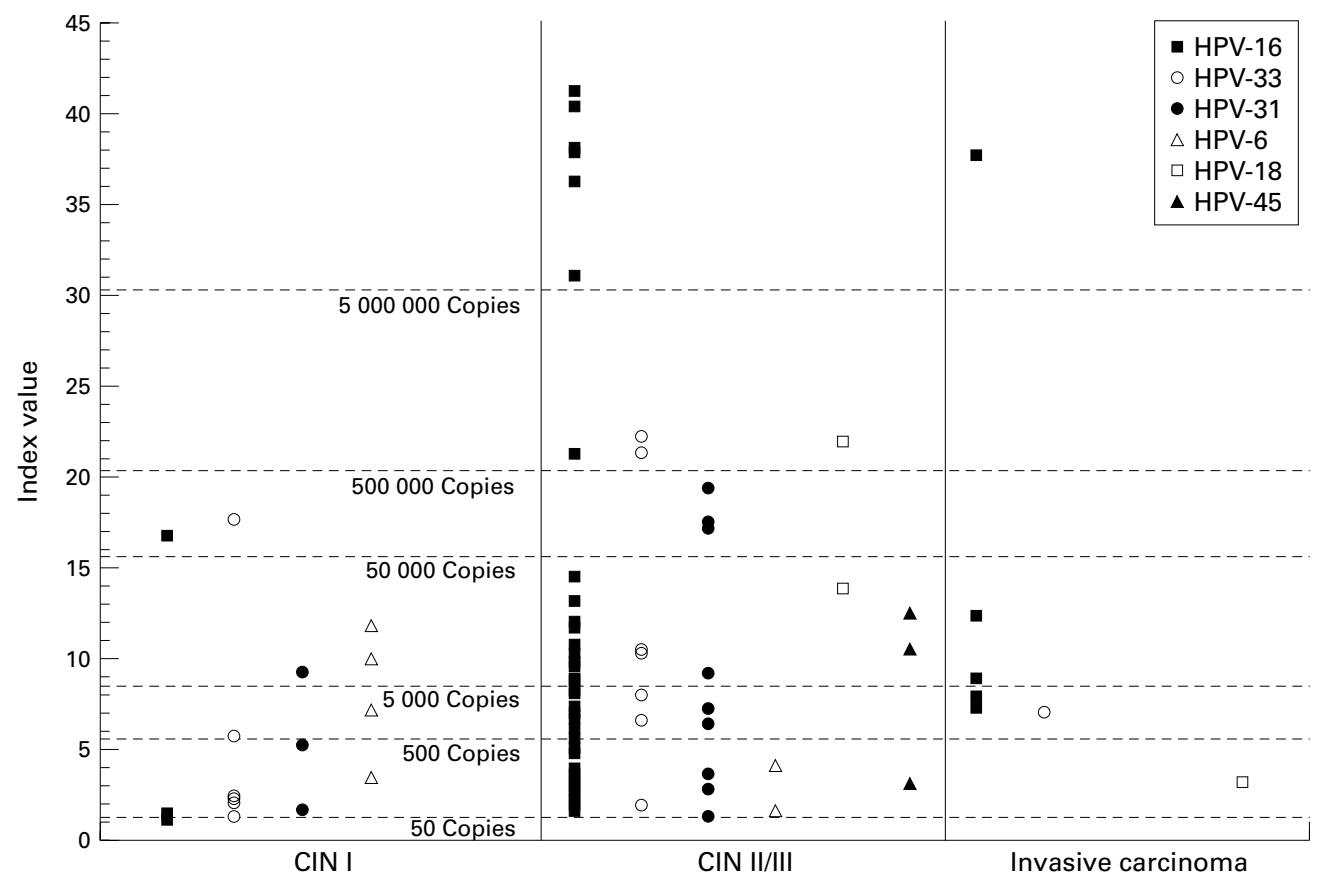

Figure 1 Distribution of single type specific human papillomavirus (HPV) and HPV DNA content in different cervical lesions: index values, as determined by polymerase chain reaction-enzyme linked immunosorbent assay, in relation to genome copy number obtained by an external reference titration curve. 
in the groups from CIN I to IC, respectively. However, it must be noted that the trend was mainly determined by HPV-16, which was the prevalent genotype in these patients $(57.6 \%)$ and was the only HPV genotype present in the CIN II/III and IC groups in amounts higher than $5 \times 10^{6}$ genome copies/sample.

In conclusion, our data support the observation that HPV-16 is the most common genotype detected in cervical lesions. The prevalence of high risk HPV shows the expected distribution in cervical lesions, increasing with the grade of the lesions; above all, increased HPV-16 viral load appears to be associated with increased severity of cervical disease and, therefore, HPV testing and typing might be of prognostic value. Quantitative analysis showed that HPV-16 DNA can reach much higher values than other genotypes, and that a very high HPV-16 DNA content is found only in high grade lesions. However, HPV-16 DNA load seems a specific but not sensitive diagnostic marker to define cervical disease status. ${ }^{5}$ PCR-ELISA provides a valid and sensitive diagnostic tool, readily available in laboratories for HPV testing and typing, which can also give a semiquantitative evaluation of viral load.

This work was partially supported by the target project on "Biotechnology" CNR and University of Bologna funds for selected research topics.
1 Keerti VS, Howley PM. Papillomaviruses. In: Fields BN, Knipe DM, Howley PM, et al, eds. Virology, 3rd ed. Philadelphia: Lippincott-Raven, 1996;2:2077-109.

2 Schneider A, Zahm DM, Kirchmayr R, et al. Screening for cervical intraepithelial neoplasia grade 2/3: validity of cytologic study, cervicography, and human papillomavirus detection. Am f Obstet Gynecol 1996;174:153441.

3 Cox JT, Lorincz AT, Schiffman MH, et al. Human papillomavirus testing by hybrid capture appears to be useful in triaging women with cytologic diagnosis of atypical squamous cells of undetermined significance. Am $\mathcal{F}$ Ostet Gynecol 1995;172:946-54.

4 Swan DC, Tucker RA, Tortolero-Luna G, et al. Human papillomavirus (HPV) DNA copy number is dependent on grade of cervical disease and HPV type. 7 Clin Microbiol 1999;37:1030-4.

5 Cuzick J, Terry G, Ho L, et al. Type-specific human papillomavirus DNA in abnormal smears as a predictor of high-grade cervical intraepithelial neoplasia. $\mathrm{Br} 7$ Cancer 1994;69:167-71.

6 Nindl I, Lotz B, Kühne-Heid R, et al. Distribution of 14 high risk HPV types in cervical intraepithelial neoplasia detected by a non-radioactive general primer PCR mediated enzyme immnoassay. F Clin Pathol 1999;52:1722.

7 Venturoli S, Zerbini M, La Placa M, et al. Evaluation of mmunoassays for the detection and typing of PCR ampli$143-8$

8 Manos MM, Ting Y, Wright DK, et al. Use of polymerase chain reaction amplification for the detection of genital human papillomaviruses. Cancer Cells 1989;7:209-14.

9 Resnick RM, Cornelissen MTE, Wright DK, et al. Detection and typing of human papillomavirus in archival cervical cancer specimens by DNA amplification with consensus primers. I Natl Cancer Inst 1990;82:147784 .

10 Saiki RK, Scharf S, Faloona FA, et al. Enzymatic amplification of a $\beta$-globin genomic sequence and restriction site analysis for diagnosis of sickle cell anemia. Science 1985;230:1350-4

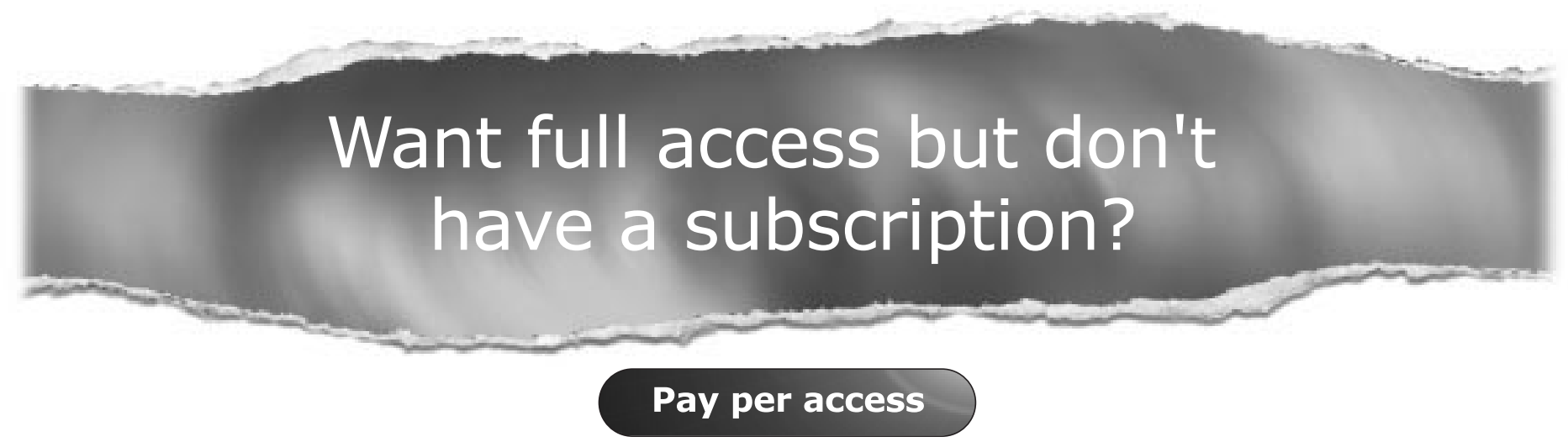

For just US $\$ 25$ you can have instant access to the whole website for 30 days. During this time you will be able to access the full text for all issues (including supplements) available. You will also be able to download and print any relevant pdf files for personal use, and take advantage of all the special features Journal of Clinical Pathology online has to offer.

\section{www.jclinpath.com}

